\title{
2010-2011 influenza seasonal vaccine, preliminary mid-season effectiveness estimates: reason for concern, confounding or are we following the right track?
}

J Puig-Barberà (puig_joa@gva.es) ${ }^{1}$

1. Vaccines Research Unit, Centre for Public Health Research, Valencia, Spain

Citation style for this article:

Puig-Barberà J. 2010-2011 influenza seasonal vaccine, preliminary mid-season effectiveness estimates: reason for concern, confounding or are we following the right track?. Euro Surveill. 2011;16(11):pii=19821. Available online: http://www.eurosurveillance.org/ViewArticle.aspx?Articleld=19821

Article published on 17 March 2011

During the last 10 years there have been major advances in influenza surveillance, vaccine production and methods to determine vaccine effectiveness (VE), influenza diagnosis by real-time polymerase chain reaction (PCR), and influenza virology. Most of these have been fostered by the threat of a possible pandemic and the planning efforts devoted to minimising its impact.

The Influenza Monitoring Vaccine Effectiveness in Europe (I-MOVE) network, funded by the European Centre for Disease Prevention and Control (ECDC), has made a substantial contribution to these efforts. Among other activities, it has endorsed,case-control test-negative studies focused on providing VE estimates for specific laboratory-confirmed influenza outcomes, especially medically attended influenza-like illness (ILI) [1-3]. As a result of this initiative, I-MOVE associates have published preliminary mid-season estimates of the VE of the 2010/11 influenza seasonal trivalent vaccine to prevent cases of medically attended ILI laboratory-confirmed for influenza $[4,5]$ : two additional preliminary reports are published in this week's issue of Eurosurveillance [6,7].

The present influenza season, which is now coming to an end, has been characterised predominantly (70-80\%) by influenza A/California/07/2009( $\left.\mathrm{H}_{1} \mathrm{~N}_{1}\right)$ like isolates. There has also been a smaller but notable proportion (15-24\%) of B/Brisbane/6o/2008 (Victoria lineage) isolates in the season thus far, but in week 9 of 2011 , they accounted for $80 \%$ of virus isolates [8],Both virus types are included in the trivalent seasonal vaccines now used in Europe $[8,9]$. Thus, the currently circulating influenza $A\left(\mathrm{H}_{1} \mathrm{~N}_{1}\right)_{2009}$ virus and the currently used vaccine are similar but not identical to the virus circulating in the autumn 2009 pandemic wave $[7,10]$ and the monovalent adjuvanted vaccines used then $[4,5,7]$.

Perhaps not surprisingly, the published VE estimates for the current seasonal vaccine [4-7] were lower that those published for the pandemic vaccine used in 2009/10 [3,11-13]. They were, however, so low that when the usual confounding factors are taken into account, the estimates are compatible with a hypothesis of no effect. This raises the question of whether the lower adjusted VE of the 2010/2011 trivalent influenza vaccine is a real phenomenon or whether it is due to confounding, mismeasurement or other unknown factors. Some of the recent studies have mentioned the possible role of antigenic drift and differing study populations $[4,6,7]$. Although these possible explanations are intuitive and plausible - and no doubt partially explain the situation - there are some other issues that also merit discussion. Moreover one needs to keep in mind that the VE of the non-adjuvanted vaccines in the pre-pandemic area was lower than that of the adjuvanted monovalent pandemic vaccine.

From the data presented in these studies, we can build a scenario in which older age, the presence of risk factors and previous vaccination in the study population were highly correlated with being vaccinated with the 2010/2011 seasonal influenza vaccine. However, the data do not show that this was linked with a differential risk of acute respiratory infection due to influenza.

It should also be remembered that negative controls were negative for influenza, but may have had other infections. Influenza viruses are one of several groups of respiratory viruses that affect us at the same time of the year and at any age. Some of the test-negative controls probably went to their physicians with symptoms such as fever, cough, malaise and dyspnoea resulting from episodes of undetected respiratory syncytial virus (RSV), rhinovirus, coronavirus, metapneumovirus, or other unidentified viral infections that could not possibly be affected by influenza vaccination, but could be affected by the same underlying factors that increase the risk of becoming an influenza case.

If the analysis is adjusted for factors associated with influenza vaccination rather than for vaccination itself, the vaccine effect will be diluted and disappear, as can be seen when comparing the crude and adjusted effects reported. The test-negative approach can be 
considered as a variant of a case-case comparison study [14], where recruitment has been prospective and within a short period, and where the most plausible factor associated with not being a true influenza case is having received influenza vaccination. For this reason any adjustment for factors correlated to vaccination must be dealt with caution $[14,15]$. The nonadjusted estimates might be a more plausible estimate of vaccine effectiveness than the adjusted results.

Even the crude VE estimates would still be confounded to the null because the study design was based purely on laboratory results. The negative controls were a mixed population of people most of whom were positive for viruses other than influenza, possibly including some false influenza-negatives and some people with non-infectious ailments. Therefore, a case-case approach comparing influenza-positive patients with those positive for other respiratory viruses (see $[14,15]$ ), with incidence sampling of both groups in periods of similar risk for influenza, would provide more realistic and convincing estimates of the influenza vaccination effect.

The authors also state that this year's study population was different from that of the previous year $[4,6,7]$. Vaccination recommendations differed, at least with respect to age, so age was a direct correlate of vaccination. Moreover, the population as a whole has had a wider exposure to influenza $A\left(\mathrm{H}_{1} \mathrm{~N}_{1}\right)_{2009}$ virus now than just a year ago [16]. Nevertheless, it is difficult to understand how this can explain the low VE results, unless this situation had an effect on the virus itself.

Another important element is therefore the influenza virus itself. Some of the recent reports on its evolution are reassuring and clearly state that the circulating viruses are well matched to the vaccine strains $[7,10,17]$, while others propose that vaccination and previous exposure lead to immunological pressure that has driven virus evolution $[7,10,17,18]$ in ways that could explain, at least in part, the observed differences between the highly effective monovalent pandemic vaccine and the lower effectiveness attributable to this year's seasonal trivalent vaccine. In fact, the reported observations point to a certain degree of mismatch between the circulating influenza $A\left(\mathrm{H}_{1} \mathrm{~N}_{1}\right) 2009$ strains and the corresponding vaccine component. The available results for the influenza $B$ strain, however, point to a reasonable VE.

In conclusion, the four preliminary mid-season studies discussed provide timely and useful information. However, it is clear that we need a better understanding of the true impact of other respiratory viruses. To this end, we need to establish active, comprehensive and continuous surveillance systems that take advantage of the advances in diagnostic tools such as multiplex real-time PCR, which will allow us to conduct more focused case-case comparison VE studies. We need, without any doubt, better influenza vaccines, in terms of viral spectrum, and effectiveness, and we cannot forget the important seasonal impact that RSV, rhinovirus, coronavirus, parainfluenza or metapneumovirus infections have in all age groups. And last but not least, comprehensive and meticulous immunological and virological surveillance must be accompanied by timely communication and publication of observations, results and their interpretation.

\section{References}

1. Valenciano M, Ciancio B, Moren A. Influenza Vaccine Effectiveness Working Group. First steps in the design of a system to monitor vaccine effectiveness during seasonal and pandemic influenza in EU/EEA Member States. Euro Surveill 2008;13(43):pii=19015. Available from: http://www. eurosurveillance.org/ViewArticle.aspx?Articleld=19015

2. Valenciano M, Kissling E, Ciancio BC, Moren A. Study designs for timely estimation of influenza vaccine effectiveness using European sentinel practitioner networks. Vaccine. 2010;28(46):7381-8.

3. Valenciano M, Kissling E, Cohen IM, Oroszi B, Barret AS, Rizzo $C$, et al. Estimates of Pandemic Influenza Vaccine Effectiveness in Europe, 2009--2010: Results of Influenza Monitoring Vaccine Effectiveness in Europe (I-MOVE) Multicentre Case-Control Study. PLos Med. 2011;8(1): PLoS Med. 2011 Jan;8(1):e1000388.

4. Pebody R, Hardelid P, Fleming D, McMenamin J, Andrews N, Robertson C, et al. Effectiveness of seasonal 2010/11 and pandemic influenza $A\left(\mathrm{H}_{1} \mathrm{~N}_{1}\right) 2009$ vaccines in preventing influenza infection in the United Kingdom: mid-season analysis 2010/11. Euro Surveill. 2011;16(6):pii=19791. Available from: http://www.eurosurveillance.org/ViewArticle. aspx?Articleld=19791

5. Castilla J, Moran J, Martinez-Artola V, Reina G, Martinez-Baz I, Garcia Cenoz M, et al. Effectiveness of trivalent seasonal and monovalent influenza $\mathrm{A}\left(\mathrm{H}_{1} \mathrm{~N}_{1}\right) 2009$ vaccines in population with major chronic conditions of Navarre, Spain: 2010/11 mid-season analysis. Euro Surveill. 2011;16(7): pii=19799. Available from: http://www.eurosurveillance.org/ViewArticle. aspx?Articleld=19799

6. Kissling E, Valenciano M, I-MOVE case-control studies team. Early estimates of seasonal influenza vaccine effectiveness in Europe, 2010/11: I-MOVE, a multicentre case-control study. Euro Surveill. 2011;16(11):pii=19818. Available from: http:// www.eurosurveillance.org/ViewArticle.aspx?Articleld $=19818$

7. Savulescu C, Jiménez-Jorge S, de Mateo S, Ledesma J, Pozo F, Casas I, et al. Effectiveness of the 2010/11 seasonal trivalent influenza vaccine in Spain: preliminary results of a case-control study. Euro Surveill. 2011;16(11):pii=19820. Available from: http://www.eurosurveillance.org/ViewArticle. aspx?Articleld $=19820$

8. Red Nacional de Vigilancia Epidemiológica, Área de Vigilancia de la Salud Pública, Centro Nacional de Epidemiología. [National Epidemiological Surveillance Network, Area Public Health Surveillance, National Epidemiology Centre]. Vigilancia de la gripe en España. Temporada 2010-2011. [Influenza surveillance in Spain. 2010-2011 season]. Week 9/2011 (27 Feb-5 Mar 2011). Madrid: Instituto de Salud Carlos III; 2011. Available from: http://www.isciii.es/htdocs/centros/ epidemiologia/pdf/grno92011.pdf.

9. Recommended viruses for influenza vaccines for use in the 2010-2011 northern hemisphere influenza season. Wkly Epidemiol Rec. 2010;85(10):81-92.

10. Mak GC, Leung CK, Cheng KC, Wong KY, Lim W. Evolution of the haemagglutinin gene of the influenza $A\left(\mathrm{H}_{1} \mathrm{~N}_{1}\right) 2009$ virus isolated in Hong Kong, 2009--2011. Euro Surveill. 2011; 16(9):pii=19807. Available from: http://www.eurosurveillance. org/ViewArticle.aspx?Articleld=19807

11. Wichmann O, Stocker P, Poggensee G, Altmann D, Walter $D$, Hellenbrand W, et al. Pandemic influenza $A\left(\mathrm{H}_{1} \mathrm{~N}_{1}\right) 2009$ breakthrough infections and estimates of vaccine effectiveness in Germany 2009-2010. Euro Surveill 2010;15(18):pii=19561. Available from: http://www.eurosurveillance.org/ViewArticle. aspx?Articleld=19561

12. Puig-Barberà J, Arnedo-Pena A, Pardo-Serrano F, TiradoBalaguer MD, Pérez-Vilar S, Silvestre-Silvestre E, et al. Effectiveness of seasonal 2008-2009, 2009-2010 and pandemic vaccines, to prevent influenza hospitalizations during the autumn 2009 influenza pandemic wave in Castellón, Spain. A test-negative, hospital-based, case-control study. Vaccine. 2010;28(47):7460-7. 
13. Hardelid P, Fleming D, McMenamin J, Andrews N, Robertson C, Sebastianpillai P, et al. Effectiveness of pandemic and seasonal influenza vaccine in preventing pandemic influenza $A\left(H_{1} N_{1}\right)_{2009}$ infection in England and Scotland 2009-2010. Euro Surveill 2011;16(2):pii=19763. Available from: http://www. eurosurveillance.org/ViewArticle.aspx?Articleld=19763

14. McCarthy N, Giesecke J. Case-case comparisons to study causation of common infectious diseases. Int J Epidemiol. 1999;28(4):764-8.

15. Rodrigues L, Kirkwood BR. Case-control designs in the study of common diseases: updates on the demise of the rare disease assumption and the choice of sampling scheme for controls. Int J Epidemiol. 1990;19(1):205-13.

16. Miller E, Hoschler K, Hardelid P, Stanford E, Andrews N, Zambon M. Incidence of 2009 pandemic influenza $A \mathrm{H}_{1} \mathrm{~N}_{1}$ infection in England: a cross-sectional serological study. Lancet. 2010;375(9720):1100-8.

17. Barr IG, Cui L, Komadina N, Lee RT, Lin RT, Deng Y, et al. A new pandemic influenza $A\left(\mathrm{H}_{1} \mathrm{~N} 1\right)$ genetic variant predominated in the winter 2010 influenza season in Australia, New Zealand and Singapore. Euro Surveill 2010;15(42): pii=19692.

Available from: http://www.eurosurveillance.org/ViewArticle. aspx?Articleld $=19692$

18. Ellis J, Galiano M, Pebody R, Lackenby A, Thompson C, Bermingham A, et al. Virological analysis of fatal influenza cases in the United Kingdom during the early wave of influenza in winter 2010/11. Euro Surveill 2011;16(1):pii=19760. Available from: http://www.eurosurveillance.org/ViewArticle. aspx?Articleld $=19760$ 